\title{
VARABILIDADE TEMPORAL DA PRECIPITAÇÃO PLUVIAL: NÍVEL DE NITROGÊNIO NO SOLO E PRODUTIVIDADE DE CULTIVARES DE GIRASSOL ${ }^{1}$
}

\author{
TEMPORAL VARIABILITY OF THE PLUVIAL PRECIPITATION: NITROGEN \\ AMOUNT IN THE SOIL OVER SUNFLOWER INCOME
}

\section{Antonio Clementino dos Santos ${ }^{2}$ Alberício Pereira de Andrade ${ }^{3}$ José Romualdo de Sousa Lima ${ }^{2}$ Ivandro de França da Silva ${ }^{3}$ Valdemir Ribeiro Cavalcante ${ }^{4}$}

\section{RESUMO}

\begin{abstract}
Objetivando avaliar os efeitos provocados pela variabilidade temporal da precipitação pluvial sobre o desenvolvimento e produtividade da cultura do girassol (Helianthus annuus $\boldsymbol{L}$.) em função da adubação nitrogenada e cultivares, realizaram-se experimentos nos anos de 1995, 1996, 1998, em Alagoinha-PB, e, no ano de 1998, em Esperança-PB, com a cultura do girassol, analisando-se quatro níveis de nitrogênio (0, 30, 60 e 90 kg.ha $\left.{ }^{-1}\right)$, dois cultivares (uma precoce e uma tardia), em blocos casualizados, com 4 repetições. Durante a condução dos experimentos, foram analisados os estádios fenológicos, fitomassa, rendimento e precipitação pluvial durante o ciclo da cultura. Com relação aos resultados, verificou-se para o municipio de Alagoinha-PB uma precipitação pluvial média anual do periodo de $1.018,6 \mathrm{~mm}$. As respostas dos tratamentos adotados para a cultura sobre as variáveis analisadas estiveram na dependência da distribuição da precipitação pluvial durante as fases de desenvolvimento dos cultivares. Foi observada também uma grande variação na resposta do girassol em relação aos níveis de nitrogênio e às cultivares em função do tempo.
\end{abstract}

Palavras-chave: produção; adubação; manejo de culturas.

\section{SUMMARY}

With the aim of analyzing the effects caused by temporal variability of rains over sunflower (Helianthus annuus L.) tillage income and development in function of nitrogen fertilization and cultivars, experiments with sunflower tillage were performed in Alagoinha-PB in the years of 1995,1996,1998 in the municipal district of Esperança-PB in 1998. In this occasion four levels of nitrogen were verified (0, 30, 60 and $90 \mathrm{~kg} . \mathrm{ha}^{-1}$ ), two cultivars (one precocious and another late) in blocks at random with four repetitions. Beyond these experiments, some data about pluvial precipitation were analyzed. During the performance of the experiments we analyzed the tillage phenological stages, biomass accumulation and income and its components. In relation to the results, was verified in Alagoinha$P B$ an annual average rains of this period (1981 - 1999) around $1.018,6 \mathrm{~mm}$. The sunflower vegetative and reproductive stages have changed according to the distribution of rains during the tillage cycle. The adopted treatment answers for tillage over the analyzed variations were depending on the distribution of rains during the tillage development stages. There was also a big variation in the tillage answers in relation to the nitrogen levels and in the cultivars in function of weather.

Key words: production; fertilization; crop management.

\section{INTRODUÇÃO}

Dentre os fatores de produção, a água é aquele que, geralmente, mais limita os rendimentos das plantas cultivadas. A região Nordeste, apesar de nela chover em média tanto quanto em muitas regiões do mundo, caracteriza-se por apresentar uma grande variabilidade de precipitação anual e, conseqüentemente, o comportamento da cultura em relação ao rendimento é muito variável.

${ }^{1}$ Parte da dissertação de mestrado apresentada junto ao Curso de Pós-graduação em Manejo de Solos e Água - Centro de Ciências Agrárias (CCA), Universidade Federal da Paraíba (UFPB).

${ }^{2}$ Engenheiro Agrônomo, Aluno de Doutorado do Programa de Pós-graduação em Tecnologias Energéticas e Nucleares - DEN/UFPE. Bolsista do CNPq. Av. Professor Luis Freire, 1000, Cidade Universitária, 50740-540, Recife, PE. E-mail: antclementino@ yahoo.com.

${ }^{3}$ Engenheiro Agrônomo, Professor do DSER do CCA/UFPB - Areia, PB

${ }^{4}$ Engenheiro Agrônomo, INTERPA, PB. 
A radiação solar e a temperatura somente podem prejudicar a cultura do girassol quando apresentam valores muitos altos. De acordo com MOTA (1983), o girassol pode suportar grande intensidade luminosa, devido a sua alta saturação, e com umidade suficientemente disponível, ainda tolera temperaturas acima de $40^{\circ} \mathrm{C}$. Segundo GONÇALVES \& TOMICH (1999), na maioria das situações, precipitação pluvial, durante o ciclo da cultura de 500 a 700mm de água, bem distribuída ao longo do ciclo, resulta em rendimentos próximos ao máximo, sendo suficiente de 250 a $400 \mathrm{~mm}$ de chuva para o seu desenvolvimento.

Nos estudos de viabilidade natural para implementação e desenvolvimento da atividade agrícola, a precipitação é um dos fatores primordiais. Segundo SILVA et al. (1998b), as limitações e possibilidades decorrentes dos solos e de outros fatores naturais, embora igualmente importantes, dependem das possibilidades e limitações climáticas. Deste modo, a exploração agrícola de uma determinada região dependerá do fornecimento adequado de água por chuva ou por irrigação (ZAFFARONI et al., 1994). Sendo a chuva aleatória, a quantidade, a distribuição e as formas de ocorrências podem variar amplamente, tornando-se de acordo com CASTRO (1994), importante e necessário o estudo de um tempo mínimo de dados de precipitação pluvial que venha refletir o comportamento de uma região.

$\mathrm{O}$ fornecimento adequado de nutrientes contribui, de forma significativa, tanto no aumento da produtividade como no aumento do custo da produção. Nesta situação, a otimização de eficiência nutricional é fundamental para ampliar a produtividade e reduzir o custo de produção. Vários fatores, como clima, solo, e suas interações afetam a absorção e a utilização de nutrientes pelas plantas (FAGERIA, 1998).

Os estudos entre cultivares e adubação, são fatores que, ao longo do tempo e em função da precipitação pluvial, permitem avaliar como se comportam as culturas, qual o manejo adequado para cada localidade e qual o modo de melhorar o rendimento sobre as condições de sequeiro. $\mathrm{O}$ objetivo foi caracterizar a produtividade e desenvolvimento de cultivares de girassol em função da variabilidade temporal da precipitação pluvial, com a utilização de cultivares e da adubação nitrogenada no solo.

\section{MATERIAL E MÉTODOS}

Para estudar a variabilidade temporal foram lançados três anos de plantio com girassol (1995, 1996 e 1998), na Estação Experimental da
Empresa Estadual de Pesquisa Agropecuária da Paraíba (EMEPA-PB), localizada no município de Alagoinha-PB, Microrregião de Guarabira, com clima As' de Köppen, que se caracteriza por ser quente e úmido, com chuvas de outuno-inverno, com precipitação média anual de $1.100 \mathrm{~mm}$, altitude de 140m, em solo classificado como Podzólico Vermelho-amarelo, textura argilosa (BRASIL, 1972).

Foram utilizados dois cultivares de girassol (precoce e tardia) para cada área experimental; 1995 (plantio, 30/04 - colheita, 29/07) e 1996- (plantio, 20/03 - colheita) 25/06 BRG 89 V2000 e M 702), enquanto para o ano de 1998 (plantio, 05/05 - colheita, 19/08) foram utilizados aos cultivares M 734 e M 742. Para cada área estudada, o experimento foi instalado em arranjo fatorial $(2 \times 4)$, constituídas de blocos casualizados, com 4 repetições, totalizando-se 32 parcelas de $3 \times 5 \mathrm{~m}$, onde foram distribuídos os 4 níveis de nitrogênio $0, \quad 30,60,90 \mathrm{~kg} \cdot \mathrm{ha}^{-1}$ nos cultivares estudados. As doses de nitrogênio foram aplicadas $1 / 3$ na semeadura $\left(0,10,20,30 \mathrm{~kg} \cdot \mathrm{ha}^{-1}\right)$ e a outra parte $(2 / 3)$ em cobertura $\left(0,20,40,60 \mathrm{~kg} \cdot \mathrm{ha}^{-1}\right)$ aos 30 dias depois da emergência.

$\mathrm{O}$ espaçamento utilizado foi $0,80 \mathrm{x}$ 0,20m, população de 62.500 plantas por hectare. As determinações das precipitações pluviais ao longo dos anos foram realizadas por meio de leituras diárias realizadas em pluviômetros instalados em cada área experimental. Durante todo o ciclo fenológico, uma vez estabelecidas as plantas, semanalmente, determinaram-se as fases de desenvolvimento vegetativo e reprodutivo das duas variedades de girassol, segundo descrições de SCHNEITER E MILLER (1981); sendo também determinados a acumulação de fitomassa, rendimento e seus componentes.

\section{RESULTADOS E DISCUSSÃO}

Com relação à distribuição interanual da precipitação pluvial, observa-se que $75,3 \%$ do total da precipitação pluvial, concentram-se nos meses de março - agosto, o que representa em média $767,2 \mathrm{~mm}$ (Tabela 1). A série climatológica estudada forneceu para a microrregião de Guarabira-PB a precipitação média anual de $1.028 \mathrm{~mm}$, com o ano mais chuvoso, 1986 que apresentou um total de $1709,5 \mathrm{~mm}$ e o ano menos chuvoso 1998, com 531,3mm. Observa-se que o início das chuvas é variável de ano para ano, ficando o plantio das culturas anuais em condições de chuvas naturais, dependente do início do período chuvoso. No entanto, na figura 1 , observa-se que a distribuição da 
Tabela 1 - Precipitação acumulada no período de março a agosto dos anos de 1981 a 1999, no município de Alagoinha.

\begin{tabular}{|c|c|c|c|c|}
\hline Ano & $\begin{array}{c}\text { Total } \\
\text { anual }\end{array}$ & Início das chuvas & Março - Agosto & Total \\
\hline & $\mathrm{mm}$ & dia/mês & $\mathrm{mm}$ & $\%$ \\
\hline 1981 & 857,7 & $12 / 03$ & 523 & 60,9 \\
\hline 1982 & 1001 & $08 / 04$ & 672 & 67,1 \\
\hline 1983 & 909 & $03 / 02$ & 601 & 66,1 \\
\hline 1984 & 943 & $26 / 03$ & 701 & 79,3 \\
\hline 1985 & 1.598 & $10 / 02$ & 1.099 & 68,8 \\
\hline 1986 & 1.709 & $01 / 03$ & 1.117 & 65,3 \\
\hline 1987 & 825 & $14 / 03$ & 696 & 84,4 \\
\hline 1988 & 1.178 & $09 / 03$ & 926 & 78,6 \\
\hline 1989 & 1.182 & $25 / 03$ & 1.067 & 90,3 \\
\hline 1990 & 694 & $14 / 04$ & 579 & 83,4 \\
\hline 1991 & 758 & $29 / 03$ & 648 & 85,5 \\
\hline 1992 & 1.182 & $11 / 02$ & 807 & 68,3 \\
\hline 1993 & 850 & - & 663 & 78,0 \\
\hline 1994 & 1.520 & $15 / 03$ & 1.154 & 75,9 \\
\hline 1995 & 1.177 & $16 / 02$ & 916 & 77,8 \\
\hline 1996 & 1.048 & $24 / 02$ & 791 & 75,5 \\
\hline 1997 & 889 & $12 / 03$ & 640 & 72,0 \\
\hline 1998 & 531 & $09 / 05$ & 465 & 87,6 \\
\hline 1999 & 689 & - & 513 & 74,4 \\
\hline Médias & 1.028 & - & 767 & 75 \\
\hline
\end{tabular}

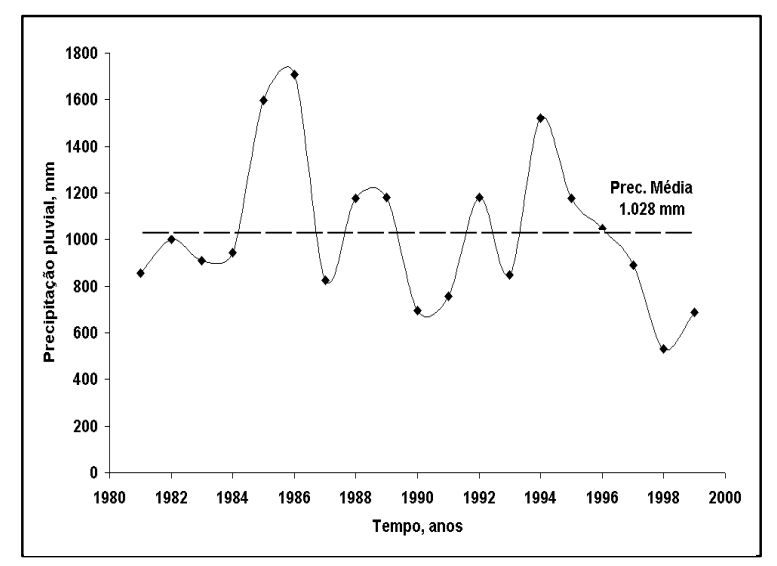

Figura 1 - Precipitação pluvial anual no período de 1981 a 1999 em Alagoinha - PB.

precipitação no decorrer do tempo é muito variável, com valores muito discrepantes em relação à precipitação média anual.

Os maiores problemas na variação em torno da precipitação média anual estão na concentração de vários valores que ocorrem continuamente, abaixo da média, com reflexos diretos no armazenamento de água no solo e na sua disponibilidade para as culturas, conforme afirmam FARIA et $\boldsymbol{a l}$. (1993) a respeito da insuficiência ou má distribuição da precipitação pluvial, como causa principal das frustrações de safras agrícolas. Com relação à distribuição da precipitação pluvial no decorrer do tempo, constata-se que existe uma grande variação tanto de ano para ano, como também na distribuição da precipitação pluvial durante o período chuvoso. Essa notável irregularidade na dinâmica atmosférica das regiões tropicais já fora constatada por CUNHA (1996), ao observar comportamentos distintos, resultando totais de chuva diferentes e afastados dos valores normais em cada ano.

Em relação à chuva, talvez o aspecto mais importante para a agricultura em geral, além de sua quantidade e sua distribuição, seja a sua freqüência, isto é, o número de dias dentro de um mês ou estação, no qual ocorre esse evento. Segundo ASSIS (1991) e KLEPPER et al. (1989), as precipitações pluviais nas regiões tropicais não são distribuídas em torno da precipitação média, mas de maneira irregular, com grande desvio em relação à mesma, o que por sua vez, pode inviabilizar a produção de produtos agrícolas, em agricultura dependente de chuvas naturais. Para SILVA et al. (1998a), a precipitação pluvial e a evapotranspiração potencial são considerados aspectos importantes, pois, pelo confronto destes parâmetros, é possível determinar a disponibilidade hídrica climática ou a precipitação efetiva. Como não foi determinada a evapotranspiração nas áreas experimentais, a precipitação pluvial (distribuição e quantidade) pode dar uma idéia da disponibilidade hídrica das áreas estudadas para a cultura do girassol nos experimentos realizados. Porém, sabe-se bem que a média dos dados pluviométricos não é necessariamente um bom parâmetro para a estimativa da produção das culturas, porque a variação dos totais mensal e anual em torno da média é muito grande (ASSAD \& CASTRO, 1991).

\section{Cultivar}

O efeito dos cultivares de girassol sobre a produtividade média anual em função da quantidade da precipitação pluvial durante o ciclo fenológico da cultura encontra-se na figura 2. Na figura 2A, observase que a produtividade dos cultivares diminuiu com a diminuição da precipitação. De acordo com FAGERIA (1989), a variabilidade genética das plantas, refere-se as características hereditárias de uma espécie vegetal ou cultivar, que apresenta diferença de crescimento ou produção em comparação com outra espécie ou cultivar, sob condições de ambiente ideais ou adversas. Devido à exigência nutricional ser variável entre cultivares da mesma espécie, é comum observar-se acumulação de biomassa diferenciada sob as mesmas condições de adubação nitrogenada para o mesmo ano agrícola (Figura 4). 


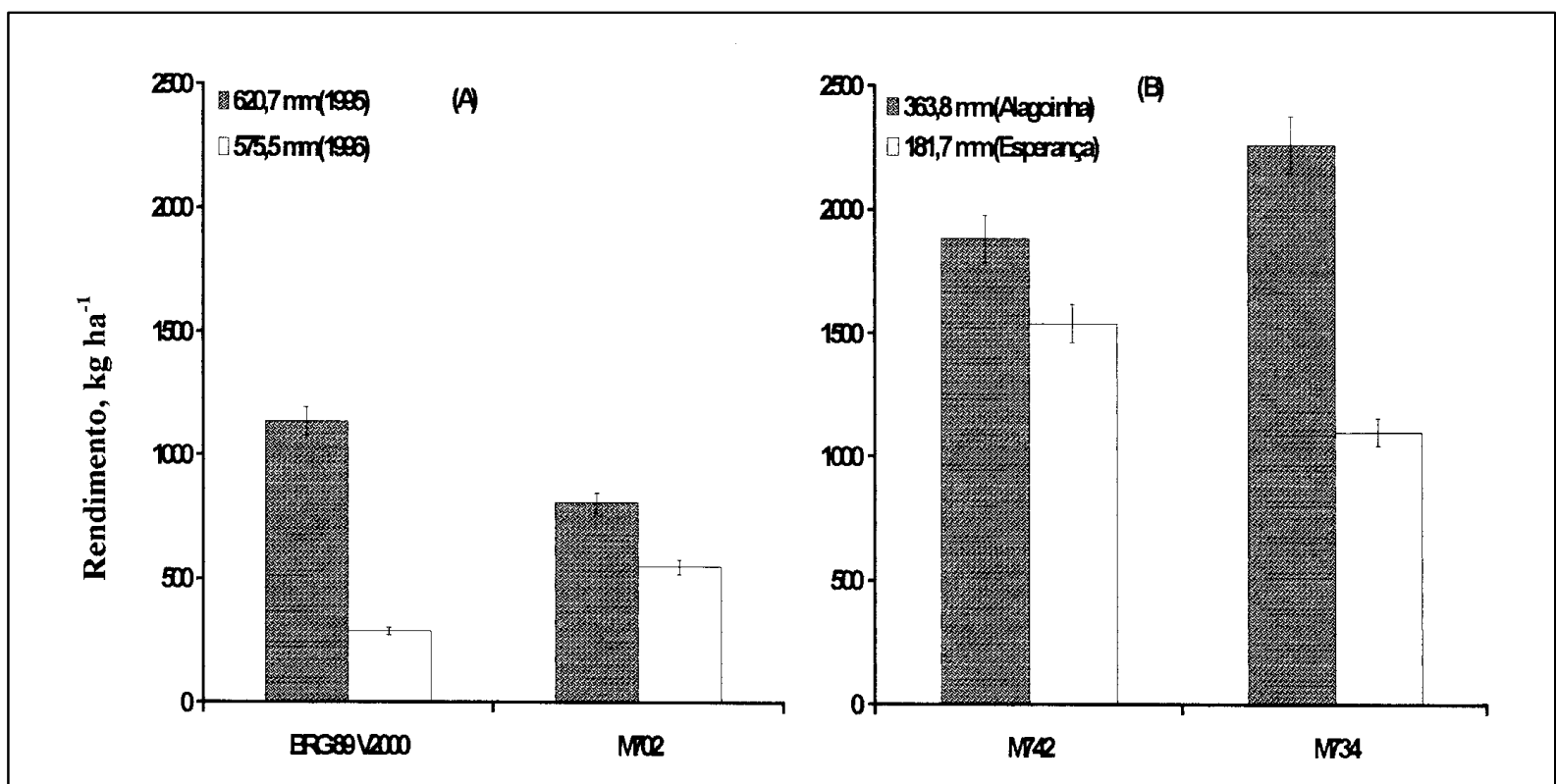

Figura 2 - Efeito dos cultivares de girassol sobre a produtividade média anual de aquênios em função da precipitação pluvial acumulada durante o ciclo da cultura. (A) Alagoinha-PB (B) Alagoinha e Esperança-PB. As barras verticais indicam o desvio padrão da média.

\section{Nitrogênio}

O efeito da adubação nitrogenada sobre a acumulação de biomassa do girassol em função da cultivar para as diferentes quantidades de precipitações, encontra-se na figura 3. Observa-se no geral que cada cultivar respondeu de forma diferenciada ao acúmulo de fitomassa com relação à precipitação acumulada.

No cultivo do girassol (condições de sequeiro), a resposta da acumulação de biomassa, aos níveis de nitrogênio no solo, está na dependência da distribuição da precipitação pluvial durante os diferentes estádios fenológicos da cultura, ou seja, os dados mostram que as respostas dos cultivares de girassol à adubação nitrogenada estão condicionadas à distribuição da precipitação nos anos estudados, pelo menos nas condições edafoclimáticas em que foram conduzidos os experimentos. Conseqüentemente, o suprimento adequado de água é necessário para o crescimento vigoroso das plantas (DOORENBOS \& KASSAM, 1994).

De acordo com FAGERIA (1998), a deficiência hídrica causa redução de vários processos fisiológicos e bioquímicos na planta, como fotossíntese, alongamento das células e fixação biológica de $\mathrm{N}_{2}$. Com base nos resultados, as respostas de acumulação de fitomassa apresentaramse com comportamento diferenciado em função da adubação nitrogenada e da precipitação acumulada, isto é, o fator responsável por esta variação não é a quantidade total da precipitação pluvial durante o ciclo da cultura e sim a distribuição desta precipitação durante o estádio fenológico das culturas.

O efeito da adubação nitrogenada sobre a produtividade do girassol em função dos cultivares, para as diferentes quantidades de precipitações pluviais durante o ciclo da cultura encontra-se na figura 4. Em experimento de campo, a produtividade é o melhor parâmetro para avaliação da eficiência nutricional em culturas anuais. No entanto, o rendimento das culturas em sistema de sequeiro, está na dependência de diversos fatores (precipitação pluvial, adubação, características químicas e físicas do solo, etc.) que interagindo entre si, possibilitam maior ou menor rendimento da cultura. Conforme resultados, verifica-se a importância da precipitação pluvial sobre o rendimento de aquênios de girassol. Estes fatores são ligados às condições ambientais como clima, solo e planta. Segundo MUNDSTOCK \& ZAGONEL (1994), o girassol responde à maior disponibilidade de nitrogênio no solo, aumentando sua área foliar, sendo a resposta variável conforme o genótipo.

Os dados dos experimentos permitem constatar que as respostas dos cultivares no decorrer do tempo são muito inconstantes. Nas condições climáticas da região, fica difícil informar qual a melhor cultivar, se precoce ou tardia, pois a resposta da cultivar, em termos de rendimento, depende muito da distribuição da precipitação e de suas características. Os cultivares tardios evidenciam 


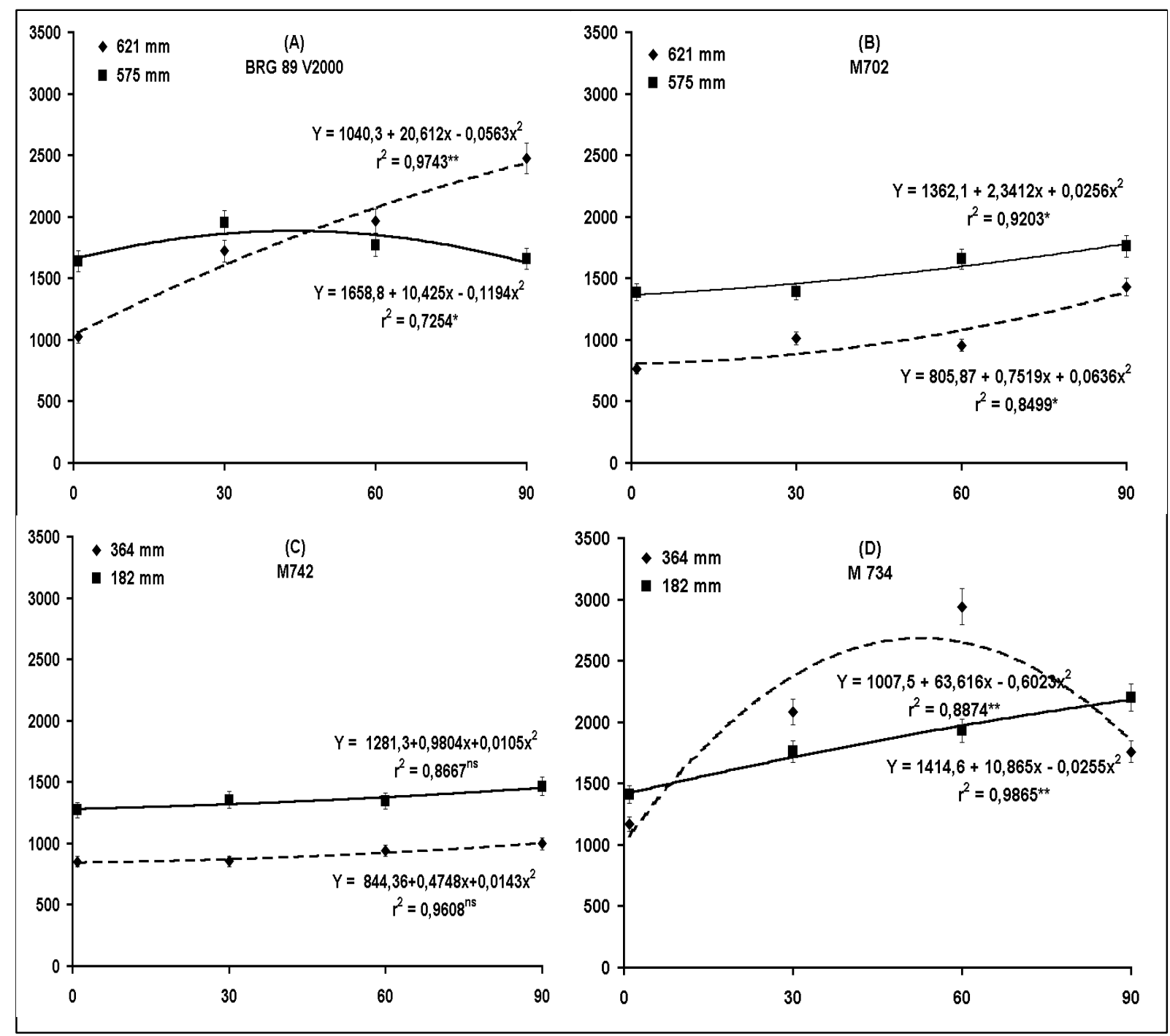

Figura 3 - Efeito da adubação nitrogenada sobre a acumulação de fitomassa do girassol em função do cultivar em condições de sequeiro. Cada ponto representa a média de 4 repetições. As barras verticais indicam o desvio padrão da média. • Precipitação pluvial durante o ciclo da cultura.

maior estabilidade de comportamento em relação às precoces no que diz respeito ao rendimento, como verificaram BARNI et al. (1989).

De acordo com SANTOS et al. (1999), o efeito do nitrogênio sobre o rendimento ou acumulação de biomassa depende da quantidade de água e da distribuição da precipitação durante o ciclo da cultura. No entanto, observa-se pelas figuras acima referidas, que a cultura do girassol também é caracterizada por apresentar alta capacidade produtiva. De acordo com ZAFFARONI et al. (1994) o girassol é considerado uma cultura que tem relativa tolerância à seca, produzindo satisfatoriamente em situações que poderiam limitar o desenvolvimento de outras culturas, como o milho e o sorgo.
Efeito da distribuição da precipitação pluvial em relação às fases (estádios) fenológicos do girassol.

Verifica-se grande diferença quantitativa da chuva durante o ciclo da cultura e uma grande diferença na distribuição da precipitação nos quatros períodos analisados (Figura 5). A distribuição da precipitação durante o ciclo dos cultivares de girassol variou de ano para ano e em relação às localidades. Dependendo da cultivar e do clima, os quais determinam a duração da estação de crescimento e a demanda de água, pode este consumo aumentar nas fases do estabelecimento ao florescimento, sendo as cultivares e as variações das precipitações os principais fatores responsáveis pela variação de desenvolvimento das culturas. Segundo 


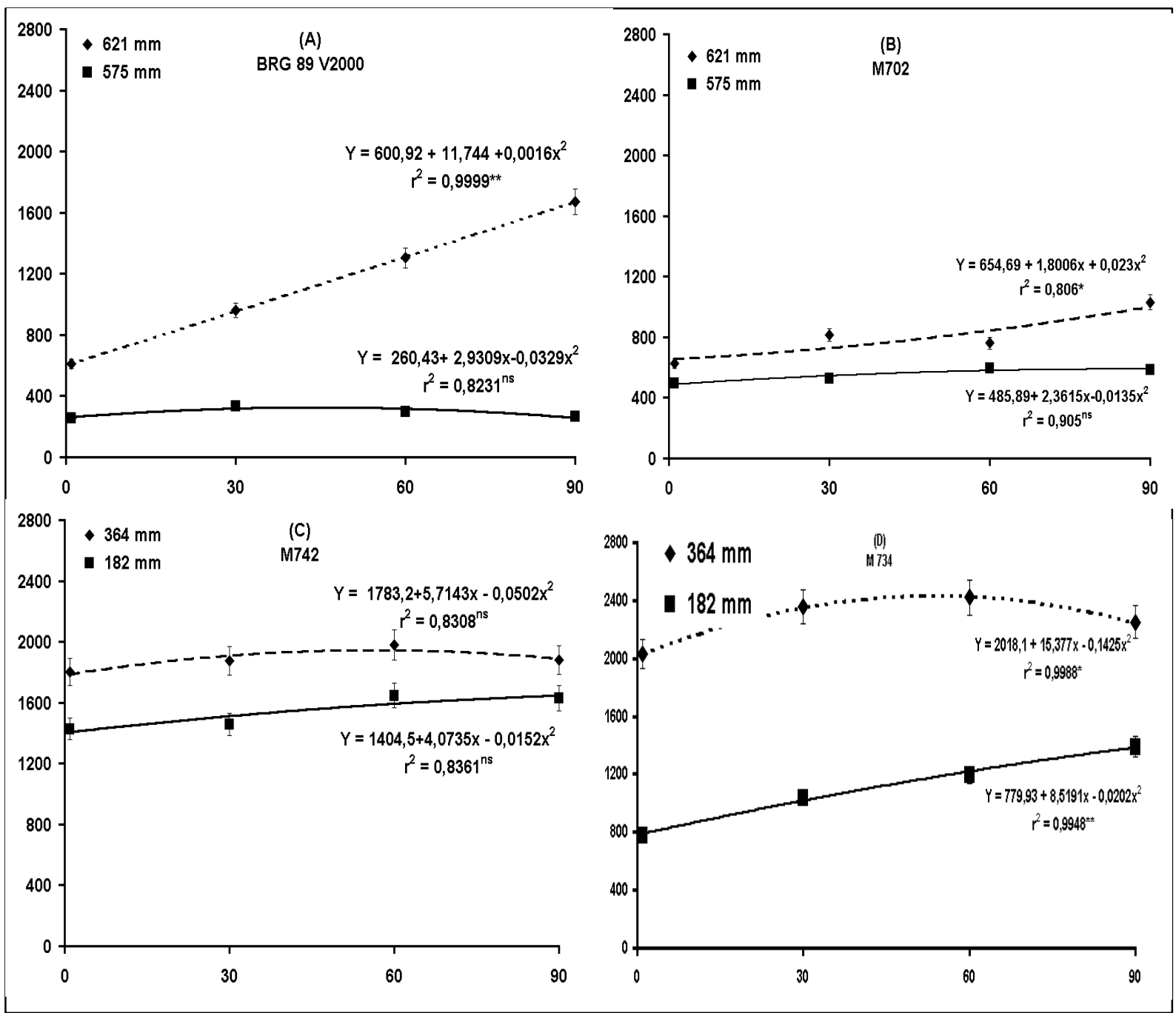

Figura 4 - Efeito da adubação nitrogenada sobre a produtividade do girassol em função do cultivares, em condições de sequeiro. Cada ponto representa a média de 4 repetições. As barras verticais indicam o desvio padrão da média. *Precipitacão pluvial durante o ciclo da cultura.

ZAFFARONI et al. (1994), as fases de desenvolvimento do girassol se distinguem quanto ao consumo de água. O que mais uma vez vem comprovar os efeitos dos fatores edafoclimáticos sobre esta espécie.

\section{CONCLUSÕES}

Os veranicos nos períodos chuvosos que ocorrem no município de Alagoinha (microrregião de Guarabira-PB) sugerem a necessidade de irrigação suplementar para suprir a demanda hídrica das culturas;

O valor médio de acumulação anual da precipitação pluvial não é um bom parâmetro para o planejamento agrícola, pois a distribuição da precipitação, caracteriza-se por notável irregularidade;

Independente do cultivar e do nível de nitrogênio, a produtividade da cultura está diretamente relacionada com a disponibilidade de água no solo.

\section{AGRADECIMENTOS}

À CAPES pela bolsa concedida e ao Curso de Pósgraduação em Manejo de Solos e Água do CCA/UFPB pelo apoio a este trabalho.

Ciência Rural, v. 32, n. 5, 2002. 


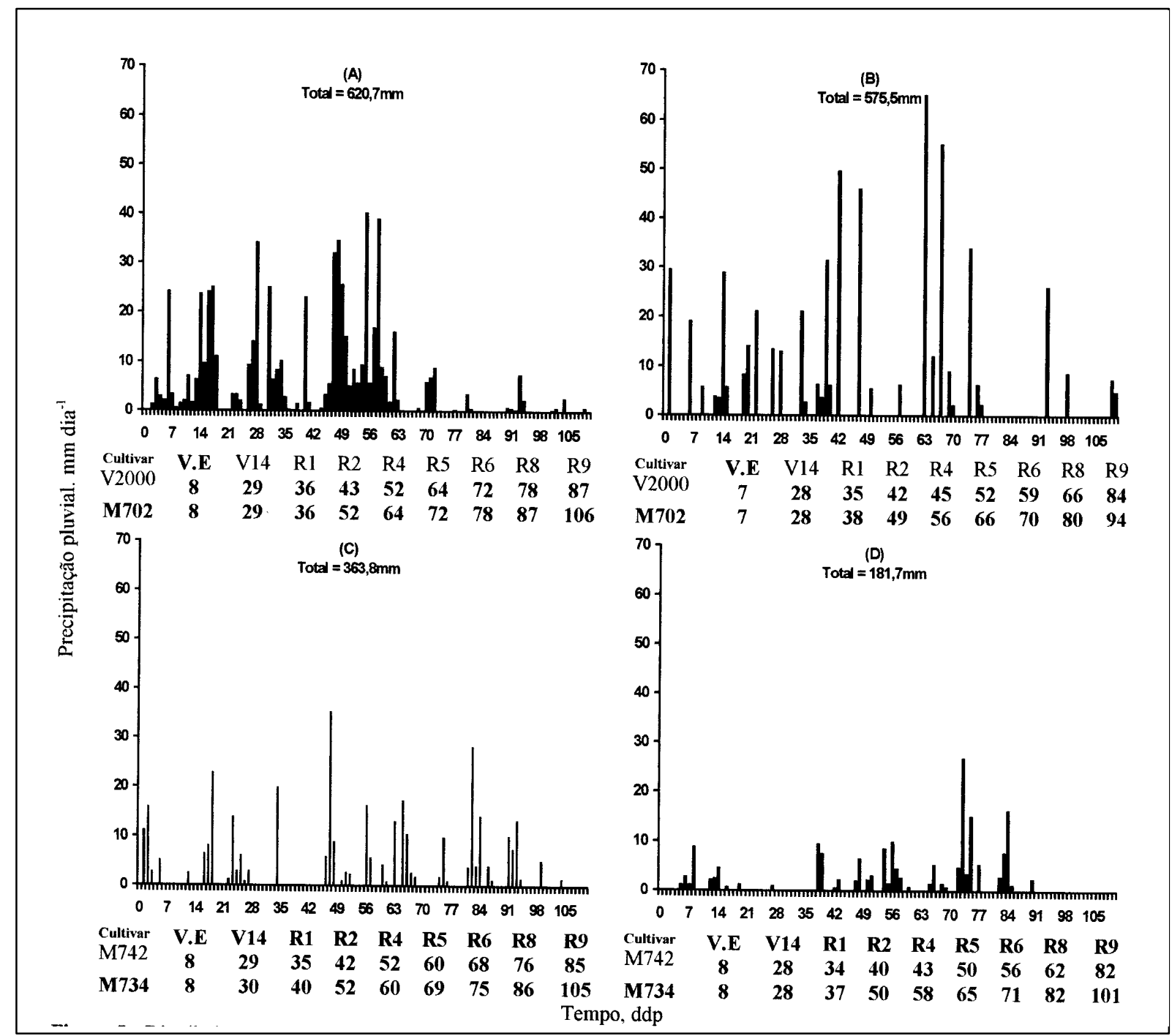

Figura 5 - Distribuição da precipitação pluvial durante a condução dos experimentos com girassol.. (A) 30/04 - 29/07 de 1995 - AlagoinhaPB, (B) 20/03 - 25/06 de 1996 - Alagoinha-PB, (C) 05/05 - 19/08 de 1998 - Alagoinha-PB, e (D) 05/05 - 19/08 de 1998 Esperança-PB. ddp - dias depois do plantio, VE e V14 - fase vegetativa e R1...R9 - fase reprodutiva.

\section{REFERÊNCIAS BIBLIOGRÁFICAS}

ASSAD, E.D., CASTRO, L.H.R. de. Análise freqüêncial da pluviometria para a estação de Sete Lagoas-MG. Pesquisa Agropecuária Brasileira. Brasília, v.26, n.3. p.397-402, 1991.

ASSIS, F.N. de. Modelagem da ocorrência e da quantidade de chuva e de dias secos em Piracicaba-SP e Pelotas-RS. Piracicaba, 1991. 134p. Tese (Doutor em Agronomia) Escola Superior de Agricultura "Luiz de Queiroz", Universidade de São Paulo, 1991.

BARNI, N.A., ZANOTELLI, V., MENDES, I.O., et al. Introdução e avaliação de cultivares de girassol em duas regiões fisiográficas do Rio Grande do Sul. Agron Sulriograndense, Porto Alegre, v.25, n.2. p.99-128, 1989.
BRASIL. Ministério da Agricultura. Equipe de pedologia e fertilidade do solo. Divisão de Agrologia - SUDENE Levantamento exploratório - Reconhecimento de solos do Estado da Paraíba. Rio de Janeiro, 1972. 670p. (Boletim Técnico, 15).

CARLESSO, R. Plantio direto em solos arenosos: alternativas de manejo para a sustentabilidade agropecuária. Santa Maria: Departamento de Solos, Programa de Pós-Graduação em Agronomia CCR-UFSM - Curso de atualização em recomendação de adubação e calagem, 1998. Disponibilidade de água às plantas em solos arenosos, 1998. p.21-51.

CASTRO, R. Distribuição probabilística da freqüência de precipitação na região de Botucatu-SP. Botucatu, 1996. 101p. Dissertação (Mestrado em Agronomia) - Faculdade de Ciências Agronômicas. Universidade Estadual Paulista, 1994. 
CUNHA, A.R. da. O modelo gama de probabilidade aplicado ao estudo da distribuição da chuva na região administrativa de Bauru-SP. Botucatu, 1996. $88 \mathrm{p}$. Dissertação (Mestrado em Agronomia) - Faculdade de Ciências Agronômicas, Universidade Estadual Paulista, 1996.

DOORENBOS, J., KASSAM, A.H. Efeito da água no rendimento das culturas. Campina Grande: UFPB, 1994. 306p. (estudos da FAO: Irrigação e Drenagem 33, Tradução por H.R. Gheyi; A.A. Sousa; F.A. Damasceno; e J.F. de Medeiros - Tradução de Yield response to water)

FAGERIA, N.F. Otimização da eficiência nutricional na produção das culturas. Revista Brasileira de Engenharia Agrícola e Ambiental, Campina grande. v.2, n.1, p.6-16, 1998.

FAGERIA, N.K. Solos tropicais e aspectos fisiológicos das culturas. Brasília : EMBRAPA-CNPAF, 1989. 425p.

FARIA, R.T. de, BOISVERT, J., COSTA, A.C.S. da, et al. Utilização de técnicas de modelagem na estimativa da umidade do solo sob culturas anuais no Estado do Paraná. Londrina : Instituto Agronômico do Paraná, 1993. 39p.

GONÇALVES, L.C., TOMICH, T.R. Utilização do girassol como silagem para alimentação bovina. In: REUNIÃO NACIONAL DE PESQUISA DE GIRASSOL, 13; SIMPÓSIO NACIONAL SOBRE A CULTURA DO GIRASSOL, 1, 1999, Itumbiara, GO. Anais... Itumbiara, GO : EMBRAPA, 1999. p.21-30.

KLEPPER, C.M., SCIAN, B.V., PIERINI, J.O. Time ande space variability of rainfall in Central East Argentina. Journal of Climate, v.2, n.1, p.39-47, 1989.
MOTA, F.S. da. Meteorologia agrícola. São Paulo : Nobel, 1983. 376p.

MUNDSTOCK, C.M., ZAGONEL, J. Perfil da área foliar de duas cultivares de girassol sob doses e épocas de aplicação de nitrogênio em cobertura. Pesquisa Agropecuária Brasileira, Brasília, v.29, n.6, p.847-851, 1994.

SANTOS, A.C. dos, LIMA, J.R. de S., CAVALCANTE, V.R. et al. Avaliação do rendimento do girassol em função da variabi0lidade espacial e temporal com a utilização de adubação nitrogenada e cultivares. REUNIÃO NACIONAL DE PESQUISA DE GIRASSOL, 13; SIMPÓSIO NACIONAL SOBRE A CULTURA DO GIRASSOL, 1, 1999, Itumbiara, GO. Anais... Itumbiara : EMBAPA, 1999. p.111-114.

SCHNEITER, A.A., MILLER, J. F. Description of sunflower growth stages. Crop Science, v.21, p.901-903, 1981

SILVA, B.B. da, SOUZA, C.B., RAO, T.V.R., et al. Efeitos do déficit hídrico sobre a fenometria e a tecnologia de fibra do algodoeiro herbáceo. Revista Brasileira de Engenharia Agrícola e Ambiental, Campina Grande, v.2, n.1, p.42-46, 1998a.

SILVA, A.M. da, ASSAD, E.D., MATTOS, A. et al. Variação espaço-temporal da disponibilidade hídrica climática no Estado de Goiás. Pesquisa Agropecuária Brasileira., Brasília, v.33, n.5, p.605-612, 1998 b.

ZAFFARONI, E., SILVA, M.A.V., AZEVEDO, P.V. de Potencial agroclimático da cultura do girassol no Estado da Paraíba II. Necessidade de água. Pesquisa Agropecuária Brasileira, Brasília, v.29, n.10, p.1493-1501, 1994. 